\title{
Wheel Device
}

National Cancer Institute

\section{Source}

National Cancer Institute. Wheel Device. NCI Thesaurus. Code C51067.

A mechanical device consisting of a spoked, circular rim or solid disk designed to rotate on an axle or shaft. 